\title{
Evaluation of Disease Index, Colon Damage Score, and Microbial Analysis of Intestinal Flora after Treatment with the Novel Test Formulation in TNBS-Induced Colitis in Sprague Dawley Rats
}

ISSN: 2637-7632

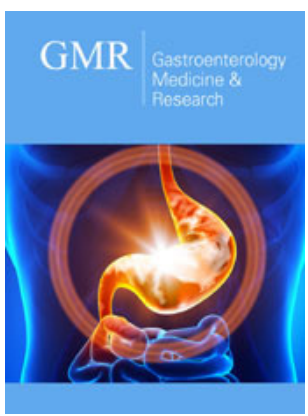

*Corresponding author: Snehasis Jana, Trivedi Science Research Laboratory Pvt. Ltd., Thane-West, Maharashtra, India

Submission: 毕 May 03, 2021

Published: 侮 May 21, 2021

Volume 5 - Issue 5

How to cite this article: Mahendra Kumar Trivedi, Snehasis Jana. Evaluation of Disease Index, Colon Damage Score, and Microbial Analysis of Intestinal Flora after Treatment with the Novel Test Formulation in TNBS-Induced Colitis in Sprague Dawley Rats. Gastro Med Res. 5(5). GMR. 000624. 2021.

DOI: 10.31031/GMR.2021.05.000624

Copyright@ Snehasis Jana, This article is distributed under the terms of the Creative Commons Attribution 4.0 International License, which permits unrestricted use and redistribution provided that the original author and source are credited.

\author{
Mahendra Kumar Trivedi ${ }^{1}$ and Snehasis Jana ${ }^{2 *}$ \\ ${ }^{1}$ Trivedi Global, Inc, Henderson, Nevada, USA \\ ${ }^{2}$ Trivedi Science Research Laboratory Pvt. Ltd., Thane-West, Maharashtra, India
}

\begin{abstract}
The aim of the present study was to evaluate the microbial analysis, Disease Activity/Activation Index (DAI), and Colon Mucosal/Macroscopic Damage Index (CMDI) analysis after treatment with the Biofield Energy Healing/Blessing (the Trivedi Effect ${ }^{\circledR}$ ) based novel test formulation in male Sprague Dawley rats. The test formulation consists of minerals (zinc, magnesium, iron, and copper) and vitamins $\left(\mathrm{B}_{6}, \mathrm{~B}_{12}\right.$, and $\mathrm{D}_{3}$ ), which was divided into two parts. One part was denoted as the control, without any Biofield Energy Healing/Blessing Treatment, while the other part was defined as the Biofield Energy Treated/Blessed sample, which received the Biofield Energy Healing Treatment/Blessing by a renowned Biofield Energy Healer, Mr. Mahendra Kumar Trivedi. Additionally, three group of animals were also received Biofield Energy Treatment per se (day -15) under similar conditions. The gut health microbial analysis along with DAI and CMDI with the help of Elevated Plus Maze (EPM) was evaluated. The DAI score was decreased by $18.8 \%, 13.5 \%, 18.6 \%, 25.5 \%$, and $15.8 \%$ in the G5 (Biofield Energy Treated test formulation), G6 (Biofield treatment per se to animals at -15 days), G7 (Biofield Energy Treated test formulation at -15 day), G8 (Biofield Treatment per se to the animals plus Biofield Treated test formulation at -15 day), and G9 (Biofield Treatment per se to the animals plus untreated test formulation) groups, respectively as compared with the G2. EPM data showed a significant increase time spent in open arm by $436.55 \%$, $493.31 \%, 526.77 \%(p \leq 0.05), 438.61 \%$, and $133.20 \%$ in the G5, G6, G7, G8, and G9 groups, respectively as compared to the G2 group. Microbial analysis showed decrease in the count of E. coli in the G5, G6, and G8 groups, while a decrease in the Klebsiella pneumonia count was also observed in at $4^{\text {th }}$ week in all treated groups except the G5 group as compared with the G4. On the other hand, the increase of the beneficial bacteria Bacteriodes uniformis and Prevotella copra was observed in the G5 group. CMDI score was significantly reduced by $19.67 \%, 13.79 \%, 25.55 \%$ ( $p \leq 0.05), 29.47 \%(p \leq 0.05)$, and $21.63 \%$ in the G5, G6, G7, G8, and G9 groups, respectively as compared with the G2 group. Overall, the data indicated that the Trivedi Effect ${ }^{\circledR}$-Biofield Energy Healing based test formulation and Biofield Energy Treatment per se reduced the colon inflammation in the TNBS-induced colitis rats by decreasing CMDI and increased DAI along with improved gut microbial analysis.
\end{abstract}

Keywords: Biofield energy healing treatment; The Trivedi effect ${ }^{\circledast}$; Gut health; CMDI; DAI; EPM; Microbial analysis

\section{Introduction}

Healthy adult human gut (lower gastrointestinal tract) contains a plethora of microorganisms with more than 100 trillion bacteria [1] known as microbiota. They have significant role in modulation and maturation of immune system including significant regulation of mucosal physiology, construction of fatty acid short-chain, and vitamins [2]. Eubiosis is defined as the intestinal microbial balance of ecosystem, which is also characterized by the preponderance of potentially beneficial species that play a vital role in immunity. Besides, an alteration in normal flora of gut and its deviation from gut homeostasis is defined as dysbiosis, which results in a bunch of diseases such as Ulcerative Colitis (UC), colorectal cancer, and various other Inflammatory Bowel Diseases (IBDs) like Crohn's Disease (CD) and Pouchitis. Gut microbiota disruption led to inflammation, and the continued long-standing inflammation in case of IBDs results in development of colorectal 
cancer. IBD patients have been reported with an increased cancer development due to increased inflammation severity [3,4]. Various minerals and vitamins have been responsible to support the pathogenesis of IBDs and its related inflammation. However, mitigation of the disease activity/activation index (DAI), Colon Mucosal/Macroscopic Damage Index (CMDI), and microbial analysis are the key identification parameters studies for any test formulation, which signifies the ability to reduce colonic oxidative stress [5]. Accordingly, a new proprietary test formulation was formulated with a combination of the minerals and vitamins, as a complementary approach to improve the gut health, which is the combination of magnesium (II) gluconate, zinc chloride, ferrous sulphate, copper chloride (II-cupric), vitamin $\mathrm{B}_{6}$ (pyridoxine $\mathrm{HCl}$ ), vitamin $\mathrm{B}_{12}$ (cyanocobalamin), and cholecalciferol (Vit. $\mathrm{D}_{3}$ ).

Biofield Energy Healing Therapy is believed to flow throughout the material human body; however it can be measured through conventional instrumentation. Complementary and Alternative Medicines (CAMs) are one of the different segments of medicine and has shown significant results in exogenous antioxidants, which has become increasingly popular in the developed world [6-8]. Biofield Energy-Based Treatment is acceptance worldwide and National Center for Complementary and Alternative Medicine (NCCAM) has been inaugurated as the United States Federal Government's lead agency for conducting scientific research and practicing in the arena of medicine $[9,10]$. Biofield Energy Healing Treatment as a CAM approach against various disease conditions has been recommended by National Institute of Health (NIH) using different Energy therapies such as natural products, yoga, deep breathing, Tai Chi, healing touch, acupressure, Qi Gong, pilates, chiropractic/ osteopathic manipulation, acupuncture, special diets, cranial sacral therapy meditation, Reiki, massage, aromatherapy, essential oils, hypnotherapy, mindfulness, movement therapy, Ayurvedic medicine, relaxation techniques, homeopathy, guided imagery, naturopathy, progressive relaxation, traditional Chinese herbs and medicines, and applied prayer [11-13]. Every living organism possess some kind of unique energy that can be harnessed and convey it into other living and non-living things by the process of Biofield Energy Healing by altered atomic/molecular weights through possible mediation of neutrinos [14]. Biofield Energy Healing Treatment/Blessing (the Trivedi Effect ${ }^{\circledR}$ - Consciousness Energy Healing) have been studied and reported with significant outcomes in various scientific disciplines such as microbiology with altered antimicrobial sensitivity against pathogenic microbes [15-17], genetics [18,19], skin health [20,21], bone health [22-24] agricultural science $[25,26]$, immunity $[27,28]$, pharmaceuticals $[29,30]$, and materials science [31,32].

\section{Materials and Methods}

\section{Chemicals and reagents}

Copper chloride, cholecalciferol (vitamin $\mathrm{D}_{3}$ ), Sodium Carboxymethyl Cellulose (Na-CMC), sulphasalazine, and iron (II) sulfate were procured from Sigma-Aldrich, USA. Pyridoxine hydrochloride (vitamin $\mathrm{B}_{6}$ ), zinc chloride, cyanocobalamin (vitamin $\mathrm{B}_{12}$ ), and magnesium (II) gluconate were purchased from TCI, Japan. 2,4,6-trinitrobenzenesulphonic acid (TNBS) was purchased from
HiMedia, India. All the other chemicals used in this experiment were analytical grade procured from India.

\section{Experimental animals}

Randomly breed male Sprague Dawley (SD) rats with body weight around 220 to $350 \mathrm{gm}$ were used in this study. The animals were purchased from M/s. National Institute of Biologicals, India. Animals were randomly divided into nine groups based on their body weights consist of eight animals of each group. They were kept individually in sterilized polypropylene cages with stainless steel top grill having provision for holding pellet feed and drinking water bottle fitted with stainless steel sipper tube. The animals were maintained as per standard protocol throughout the experiment.

\section{Consciousness energy healing strategies}

The test formulation was divided into two parts. One part of each ingredient was considered as the normal control, where no Biofield Energy Treatment/Blessing was provided. Another part of each ingredient received Biofield Energy Treatment/Blessing by Mr. Mahendra Kumar Trivedi (known as the Trivedi Effect ${ }^{\circledR}$ ) under laboratory conditions for $\sim 3$ minutes. In addition, three different test groups as per experimental protocol, the animals were also received Biofield Energy Treatment/Blessing under laboratory conditions for $\sim 3$ minutes. The Blessing/Treatment was given to the test items remotely in the laboratory of Dabur Research Foundation, near New Delhi, India. Similarly, the control samples were subjected to "sham" healer under the same laboratory conditions for $\sim 3$ minutes. The "sham" healer did not have any knowledge about the Biofield Energy Treatment/Blessing. After that, the Biofield Energy Treated/Blessed samples were kept in the similar sealed condition. The Biofield Energy Treated/Blessed animals were also taken back to the animal experimental room for further proceedings.

\section{Experimental test groups}

The gut health oxidative stress biomarkers experiment was divided into 9 animals groups from G1 to G9. G1 denoted as the normal control with vehicle $(0.5 \% \mathrm{CMC}), \mathrm{G} 2$ group defined as colitis control, with 50\% TNBS in ethanol using intra colonic route, G3 group include reference compound i.e. sulfasalazine $(250 \mathrm{mg} /$ $\mathrm{kg}$ ), G4 group included administration of the untreated test formulation, G5 included Biofield Energy Treated test formulation, G6 group denoted as Biofield Energy Treatment per se to the animals (Day - 15) along with vehicle (0.5\% CMC), G7 group defined as the Biofield Energy Treated test formulation from day -15, G8 group included Biofield Energy Treatment per se to the animals along with Biofield Energy Treated test formulation from day -15, and G9 group animals were administered with the Biofield Energy Treatment per se (day -15) to the animals along with the untreated test formulation. 50\% TNBS in ethanol was given to the entire test group except G1.

\section{Detailed experimental procedure}

After acclimatization, animals were randomized and grouped based on their body weight after five days. Out of total nine groups, 
groups G1, G2, and G6 were treated with $0.5 \% \mathrm{w} / \mathrm{v}$ CMC-Na in distilled water for 8 weeks (day 1 to 56 ). Group 2 is TNBS induced colitis group (50\% TNBS in ethanol), while group 3 was treated orally with sulphasalazine (reference item) at a dose of $250 \mathrm{mg} /$ $\mathrm{kg}$ body weight for 8 weeks. The freshly prepared suspension of the untreated and Biofield Energy Treated Test formulation were administered orally to the G4 and G5 groups at a dose of $130.525 \mathrm{mg} / \mathrm{kg}$ for 8 weeks. Similarly, G7 and G8 groups were treated with the test formulation at a dose $130.525 \mathrm{mg} / \mathrm{kg}$ from the day of Biofield Energy Treatment (day -15 to 56), while in group G9, Biofield Energy Treated animals were treated with untreated test formulation for 8 weeks. Before the induction of experimental colitis, a short fasting preceded. The duration ranged from 12 to 18 hours, while the chronic colitis was induced by intra colonic administration of TNBS- $50 \%$ ethanol in a total volume of $400 \mu \mathrm{L}$, at a dose of $10 \mathrm{mg} / \mathrm{rat}$. TNBS was instilled by a suitable medicalgrade polyurethane catheter for enteral feeding approximately $8 \mathrm{~cm}$ proximal to the anal verge. Accordingly, TNBS injection was given on day $1,8,15,21,27,34,40,48$, and 54 . TNBS-50\% ethanol was given to all the animals from G2 to G9 groups. At interim (at week 4) and after the end of the experiment (week 8), faecal matter was collected from all the animals for microbiota analysis. Colonic segment was isolated at week 8 for the analysis of CMDI score.

\section{Assessment of Disease Activity Index (DAI)}

DAI was used to assess the clinical severity of colitis, according to the protocol used by Murano et al. [33]. The calculation was based on the daily body weight, stool consistency, and rectal bleeding. The loss of body weight was scored as follows: 0 for no weight loss; 1 for weight loss of $0 \%$ to $5 \%$; 2 for weight loss of $5 \%$ to $10 \% ; 3$ for weight loss of $10 \%$ to $20 \%$; and 4 for weight loss $>20 \%$. Stool consistency was scored as follows: 0 for normally formed pellets; 2 for pasty and semi formed pellets; and 4 for liquid stool. Rectal bleeding was scored as follows: 0 for no blood from the rectum and 4 for gross bleeding from the rectum. These scores were summed, resulting in a total clinical score ranging from 0 to 12 .

\section{Elevated Plus Maze (EPM) test}

The Elevated Plus Maze (EPM) is a widely used behavioural assay for rodents and it has been validated to assess the antianxiety effects of pharmacological agents and steroid hormones, and to define brain regions and mechanisms underlying anxietyrelated behaviour. The animal is placed at the junction of the four arms of the maze, facing an open arm, and entries/duration in each arm was recorded by a video-tracking system and observer simultaneously for 5 minutes. The test protocol of EPM in all the experimental trials were carried out under low light conditions in the unfamiliar experimental room. Each animal was gently placed in the center of the maze always facing the same open arm. All trials lasted for 5 minutes each allowing the rat to freely explore the EPM. Between each animal, the maze was thoroughly cleaned with a $70 \%$ ethanol solution and dried afterward. All experiments were carried out by the same experimenter, which has been shown to be critical in reducing data variability. The trials were video recorded, and computer analyzed with the software (Smart computer tracking program from Pan Lab Harvard) to measure time spent and no of entries in open and closed arm. The data analysis included the standard measurements such as the time spent in the open/closed arms and the numbers of entries in either the open or the closed arms were analyzed by the smart software (Pan Lab Harvard). Entries were counted, when all four paws had crossed into one of the arms.

\section{Microbial analysis of intestinal flora}

Faecal matter was collected from each animal at $4^{\text {th }}$ and $8^{\text {th }}$ week for microbiota analysis. Faecal pellets were collected in one sterile container for aerobic count and one faecal pallet in anaerobic media (Robertson cooked meat media) for anaerobic count. However, at the end of the study colonic content was lavaged with ice cold PBS and collected in sterile micro centrifuge tubes and anaerobic media for microbial analysis. The conventional method was used for aerobic and anaerobic culture. Identification and quantification of organism were done by (Aerobic and Anaerobic)-MALDI-TOF or VITEC-2 instruments.

\section{Assessment of Colon Mucosal/Macroscopic Damage Index (CMDI) score}

The assessment of the Colon Mucosal/Macroscopic Damage Index (CMDI) score was based on the area of inflammation and the presence of ulcers, according to Wallace and Keenan [34]. The colonic segments were placed on an ice-cold plate, cleaned of fat and mesentery, and blotted on filter paper. The colon was weighed and its length and width measured. The colon was opened longitudinally and scored for macroscopically visible damage on a 0-10 scale, according to the criteria described by Bell described under appearance of colon tissue. Score 0 was defined for normal, 1 for localized hyperemia with no ulcers, 2 for ulceration without hyperemia or bowel wall thickening, 3 for ulceration with inflammation at one site, 4 for two or more site of ulceration and inflammation, 5 for major site of damage extending greater than $1 \mathrm{~cm}$ along length of colon, and 6 to 10 for major site of damage extending greater than $2 \mathrm{~cm}$ along the length of colon, with score increasing by 1 for each additional $\mathrm{cm}$.

\section{Statistical analysis}

The data were expressed as mean \pm Standard Error of Mean (SEM) and subjected to statistical analysis using Sigma Plot (Version 11.0). For between two groups comparison Student's $t$-test was performed, while multiple groups analysis one-way ANOVA was performed followed by post hoc analysis by Dunnett's test. The $p \leq 0.05$ was considered as statistically significant $(n=8)$.

\section{Results and Discussion}

\section{Disease Activation/Activity Index (DAI)}

The DAI score has a prominent role in assessing the magnitude of inflammation. DAI was well defined with respect to the extent of body weight loss, stool consistency, and stool haemoccult positivity or gross bleeding in as reported in various research studies [35-37]. The animals treated with TNBS (G2) showed a significant increase 
in DAI throughout the study period as compared to the normal control (G1). The results showed variation in score with respect to TNBS injection. From first to third dose of TNBS injection, a DAI score was reached up to 9 at the mid of the study (from the $4^{\text {th }}$ to the $6^{\text {th }}$ injection) reduced DAI score (5.5 to 6.5) was observed and at the end of the study from $7^{\text {th }}$ to $9^{\text {th }}$ injection, increased DAI score was observed upto 7 in the colitis control group. The DAI score of rats treated with TNBS (G2) was $5.17 \pm 0.82$, which was significantly $(p<0.001)$ higher than that of the control (G1) group $0.07 \pm 0.04$. Sulphasalazine treatment (G3) decreased DAI score $(3.50 \pm 0.62)$, which is a $32.3 \%$ improvement when compared with G2. Untreated test formulation to the untreated rats (G4) decreased $11.6 \%$ DAI score $(4.57 \pm 0.72)$ as compared to the G2. Biofield Energy Treated test formulation to the untreated rats (G5) decreased $18.8 \%$ DAI score (4.20 \pm 0.70$)$ as compared to the G2. Biofield Energy Treatment to the rats (G6) decreased DAI score $(4.47 \pm 0.71)$ by $13.5 \%$ when compared to the G2. 15 days pre-treatment of Biofield Energy Treated test formulation (G7) decreased DAI score (4.21 \pm 0.62$)$; percentage improvement of $18.6 \%$ as compared to the G2. 15 -days pre-treatment of Biofield Energy Treated/Blessed test formulation to the Biofield Energy Treated rats (G8) showed decreased DAI score $(3.85 \pm 0.72)$. The percentage improvement was $25.5 \%$ as compared to the G2 and when compared to G4 the percentage improvement was found to be $15.8 \%$. Likewise, the untreated test formulation to the Biofield Energy Treated/Blessed rats (G9) decreased DAI score (4.55 \pm 0.72 ); percentage improvement of $12 \%$ as compared to the G2 group. In addition, disease symptoms such as diarrhea, peri-anal bleeding, and bloody stools were pronounced from a day after TNBS administration and progressively decreased. Sulphasalazine treated group showed non-significant improvement in the DAI and this effect was more prominent from mid of the study period. In the case of the rats treated with various combinations of Biofield Energy Treated/Blessed and untreated test formulation to the Biofield Energy Treated/Blessed and untreated TNBS induced animals, even though there was an initial increase in the DAI as compared to the colitis control rats after the $1^{\text {st }}$ administration of TNBS (day 2-7), there was improvement (up to $25.5 \%$ ) in DAI observed in treatment groups from $2^{\text {nd }}$ to last TNBS administration.

\section{Evaluation of Elevated Plus Maze Test (EPM)}

The Elevated Plus Maze (EPM) results were compiled on the basis of number of entries made into each arm and time spent in each arm. The results are evaluated on the basis of open arm and closed arm behavior. EPM animal model and its associated parameters are one of the most popular behavioral tests for with respect to anxiety, which is related with various disorders [38].

Open arm behavior: The experimental data suggested that the animals treated with TNBS (G2) showed a significant decrease $(p \leq 0.05)$ in the number of entries into the open arm and less time spent in open arm $(4.38 \pm 1.73$ and $7.77 \pm 3.81 \mathrm{sec})$ indicating an anxiety behavior, when compared to the normal control group (G1) $(17.86 \pm 5.97$ and $35.50 \pm 14.99 \mathrm{sec})$ (Figure 1). However, the other groups treated with the Biofield, reference compound, different combinations of the Biofield Energy Treated/Blessed and untreated test formulation to the Biofield Energy Treated/Blessed groups showed an increased number of entries into the open arm along with time spent in open arm. The time spent in the open arm was significantly increased by $195.11 \%, 436.55 \%, 493.31 \%$, $526.77 \%(p \leq 0.05), 438.61 \%$, and $133.20 \%$ in G4, G5, G6, G7, G8, and G9 groups, respectively than G2 group. Further, time spent time was increased by $81.81 \%, 101.05 \%, 112.39 \%$, and $82.51 \%$ in the G5, G6, G7, G8, and G9 groups, respectively than untreated test formulation (G4) group. Overall, 15 days pre-treatment of the Biofield Energy Treated Test formulation (G7) showed more time spent in the open arm (48.7 $\pm 13.96 \mathrm{sec})$, while Biofield Energy Treated Test formulation (G5) showed more number of entries into the open arm $(9.13 \pm 1.63)$ as compared to the G2 group. G9 showed similar effects in the number of entries into the open arm as compared with the G2 group. Similarly, G5, G6, G7, and G8 groups showed an improvement in the open arm behavior as compared to the G4 (untreated test formulation).

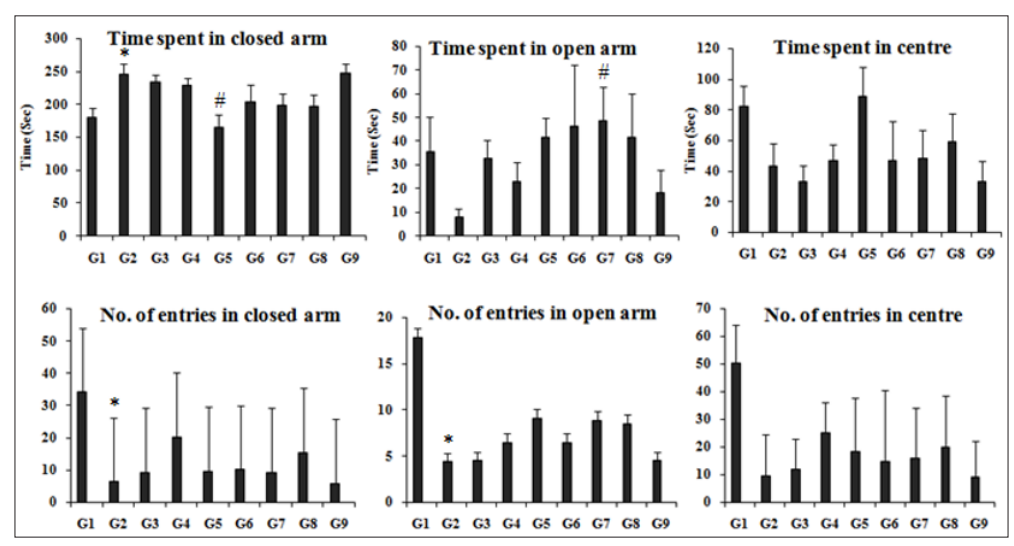

Figure 1: Effect of Biofield Energy Treated Test formulation on elevated plus maze (EPM) animal model with respect to time spent (sec) and number of entries in open and closed arms on various groups (G1 to G9). G1: Normal control; G2: Disease control; G3: Sulphasalazine, 250mg/kg; G4: Untreated test formulation; G5: Biofield Energy Treated test formulation; G6: Biofield treatment per se to animals (-15 Days); G7: Biofield Energy Treated test formulation (-15 Day); G8: Biofield Energy Treatment per se to animals plus Biofield Energy Treated test formulation (-15 Day); and G9: Biofield Energy Treatment per se to animals plus untreated test formulation. All the values are represented as mean \pm SEM $(\mathrm{n}=8) .{ }^{*} p \leq 0.05$ vs. G1 and $\# p \leq 0.05$ vs. G2. 
Close arm behavior: The experimental data suggested that the animals treated with TNBS (G2) showed a significant increase $(p \leq 0.01)$ in time spent in closed arm as well as a significant decrease $(p \leq 0.05)$ in the number of entries into close arm $(246.73 \pm 15.04 \mathrm{sec}$, $6.38 \pm 1.06)$ as compared to the normal control $(181.13 \pm 13.46 \mathrm{sec}$, $34.14 \pm 9.43$ ) (Figure 1). Biofield Energy Treated Test formulation (G5) showed a significant decrease $(p \leq 0.01)$ in the time spent in the closed arm $(164.33 \pm 19.47 \mathrm{sec})$ and a greater number of entries into the closed arm $(9.75 \pm 1.51)$ as compared to the G2 group. However, groups G3, G4, G6, G7, and G8 showed decrease time spent in the close arm and increase entries into the closed arm as compared to the G2. G9 showed similar effects in close arm behavior as compared to the colitis control (G2) group.

\section{Microbial analysis of intestinal flora}

The intestinal microbiota is considered to play a central role in the pathogenesis of IBD. The manipulation of the dysbiosis is an attractive approach for ulcerative colitis therapy. Thus, an increase in the colonies of the beneficial Bacteriodes uniformis, which is an important in numerous metabolic activities providing some level of protection from invasive pathogens and an increase in Prevotella copri that helps in the digestion of food as well as helping in keeping harmful bacteria at bay, and a reduction in the harmful Klebsiella pneumonia and E. coli may, indicate the emergence of a protective mechanism. Microbial analysis of intestinal flora was analyzed in the present study at different stages. Fourth week fecal microbiota results were compiled and the data suggested Lactobacillus murinus, E. coli and Klebsiella pneumoniae were grown in the fecal samples of different groups. However, no considerable change was observed in all treatment groups (G3 to G9) including normal control (G1) and colitis control (G2) with respect to Lactobacillus murinuscount. Increases in E. coli and Klebsiella pneumoniae count (cfu/mL) were observed in the G2 group as compared to the G1 group. Besides, sulphasalazine treated group animals showed decreased in the count of E. coli and Klebsiella pneumoniae count as compared to the G2 group. However, reduced E. coli count was observed in the G5, G6, and G8 groups. With respect to the Klebsiella pneumonia, except in the case of G5, all the treatment groups showed a considerable reduction in the microbial count. Besides, at week 8 the fecal microbiota results were analyzed and showed that Lactobacillus murinus, E. coli, Bacteriodes uniformis, Prevotella copri and Collinsella aerofaciens were grown in the fecal samples of different groups. However, no considerable changes were observed in all the treatment groups (G4 to G9) including G1 and G2 with respect to the Lactobacillus murinuscount. Increase in E. coli count was observed in fecal sample of colitis control rats as compared to the G1 group; however, there was a decrease in the E. coli count observed in G3 and G4 groups as compared to the G2 group. Bacteriodes uniformis, predominant bacteria in the rat intestine, is important in numerous metabolic activities and may provide some level of protection from invasive pathogen. Reduced count of Bacteriodes uniformis in fecal sample was observed in the colitis control group as compared to the G1 group, however, an increased colonies of Bacteriodes uniformis were observed in the G3, G4, G5, G6, and G9 groups as compared to the colitis control
(G2) group. Prevotella copri helps in the digestion of food as well as helping in keeping harmful bacteria at bay. Reduced Prevotella copri colonies were detected in the fecal samples of rats treated with the TNBS-induced group as compared to the normal control group, however, an increased colonies of Prevotella copri were observed in the G3, G4, and G5 groups similar to the G1 group. In addition, an increased Collinsella aerofaciens colonies were found in the colitis control group as compared to the normal control group. However, an increased Collinsella aerofaciens count was found in the G6 and G7 groups. The count in the case of G8 and G9 groups were similar to the colitis control group. However, no colonies of these bacteria were observed in the G1, G3, G4, and G5 groups. Various reports have published the importance of gut microbiota in different inflammatory disorders, while a microbial cell promises tremendous advances in our understanding of the microflora along with their advanced metabolic activities in the intestine [39]. Thus, overall decrease in the E. coli count was observed in the G5, G6, and G8 groups and a decrease in the Klebsiella pneumonia count at $4^{\text {th }}$ week was observed in all the treated groups except in the G5 group, the increase of the beneficial bacteria Bacteriodes uniformis and Prevotella copra was observed only in the case of the G4 and G5 groups. Biofield Energy Treatment would play a central role in managing the microbial flora in case of IBD and its related disorders.

\section{Estimation of Colon Mucosal/Macroscopic Damage Index (CMDI)}

CMDI was used to evaluate the gross appearance of the colon and assess the severity of intestinal injury. The assessment of the CMDI score was based on the area of inflammation and the presence of ulcers (Figure 2). The CMDI score of rats treated with TNBS (G2) was 6.38 \pm 0.46 , which was significantly ( $p \leq 0.001)$ higher as compared with the normal control (G1) group (0.13 \pm 0.13$)$. However, rats treated with Biofield Energy per se, reference compound, different combinations of Biofield Energy Treated and untreated test formulation to the Biofield Energy Treated and untreated TNBS-induced animals, significantly changed the CMDI score. Sulphasalazine treatment (G3) reduced the CMDI score $(5.0 \pm 0.53)$ by $21.63 \%$, while the untreated test formulation to the untreated rats (G4) showed a significant reduced value of CMDI score $(4.13 \pm 0.23)$ by $35.34 \%$ as compared with the G2 group. G5

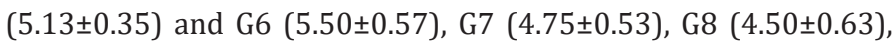
and G9 (5.0 \pm 0.57$)$ groups showed significant reduction of CMDI score by $19.67 \%, 13.79 \%, 25.55 \%(p \leq 0.05), 29.47 \%(p \leq 0.05)$, and $21.63 \%$, respectively as compared with the G2 group. Besides, colon weight $(\mathrm{mg})$, length $(\mathrm{cm})$, width $(\mathrm{cm})$ and weight/length $(\mathrm{W} / \mathrm{L})$ ratio data were analyzed, which showed that animals treated with TNBS (G2) showed significant $(p \leq 0.01)$ increase in the colon $\mathrm{W} / \mathrm{L}$ ratio and colon width as compared to the normal control (G1) group. G3 group was reported to have significant decreased $(p \leq 0.05) \mathrm{W} / \mathrm{L}$ ratio as compared to the colitis control (G2). Besides, G4 group data showed $12.29 \%$ decrease in W/L ratio as compared with the G2 group. However, G5, G6, G7, G8, and G9 groups showed significant alteration in W/L ratio as the colitis control (G2) group. Thus, CMDI assessment using macroscopical and microscopical scoring (such as CMDI and DAI) showed bowel wall thickening, 
adhesion to the surrounded tissue as well as erosion, edema and small patches of the present colon ulcer $[40,41]$. The experimental animal data suggested that CMDI score suggest significant protection from macroscopic colon damage. At the same time, the DAI score of disease control group revealed neutrophil infiltration, fibrin deposition, submucosal neutrophil migration, submucosal edema, epithelial necrosis and epithelial ulceration with the loss of epithelial villi. The clopidogrel treated group showed improvement in the above pathophysiological characteristics of the disease in both models of IBD.

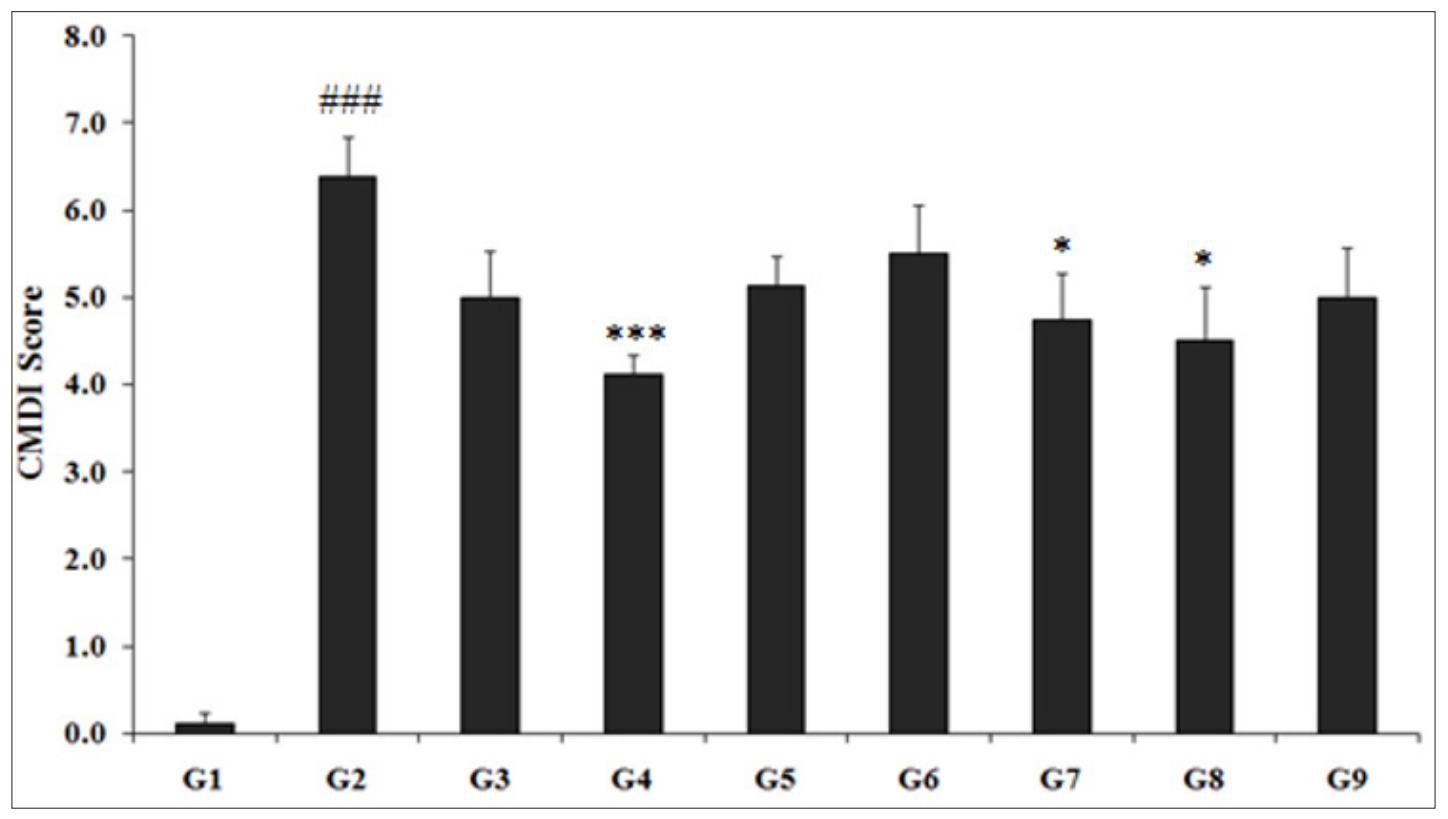

Figure 2: Effect of Biofield Energy Treated Test formulation for evaluation of colon mucosal/macroscopic damage

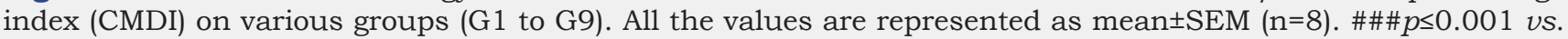
$\mathrm{G} 1,{ }^{* * *} p \leq 0.001$ vs. G2, and * $p \leq 0.05$ vs. G2.

\section{Conclusion}

The present experimental data of gut health analysis using CMDI, EPM analysis, microbial assay in TNBS-induced colitis gut health animal model recommended significant results of Biofield Energy Treatment (the Trivedi Effect ${ }^{\circledR}$ ) and the test formulation. The DAI score was significantly improved in all the groups, while maximum improvement was reported by $25.5 \%$ in G8 group as compared with the G2 group. Similarly, the EPM parameter, "time spent in open arm" was significantly increased by $436.55 \%$, $493.31 \%, 526.77 \%, 438.61 \%$, and $133.20 \%$ in G5, G6, G7, G8, and G9 groups, respectively than G2 group. In addition, microbial analysis showed a significant decrease in the count of $E$. coli in the G5, G6, and G8 groups. On the other hand, the increase of the beneficial bacteria Bacteroides uniformis and Prevotella copra was observed in the G5 group. CMDI score was significantly reduced by $19.67 \%, 13.79 \%, 25.55 \%, 29.47 \%$, and $21.63 \%$ in the G5, G6, G7, and G9 groups, respectively as compared with the G2 group. Thus, the present research findings showed that the Biofield Energy Treated test formulation and Biofield Energy Healing Treatment per se to the animals significantly enhanced gastrointestinal microflora and overall gut health. Therefore, the Biofield Energy Treated test formulation significantly effective as gut health product, which can be act as a Complementary and Alternative Medicine (CAM) and would be used for various autoimmune disorders such as Systemic Lupus Erythematosus, Fibromyalgia, Aplastic Anemia,
Addison Disease, Graves' Disease, Celiac Disease (gluten-sensitive enteropathy), Dermatomyositis, Hashimoto Thyroiditis, Multiple Sclerosis, Reactive Arthritis, Vasculitis, Asthma, Pernicious Anemia, Scleroderma, Type 1 Diabetes, Psoriasis, Chronic Fatigue Syndrome Myasthenia Gravis, Rheumatoid Arthritis, Sjogren Syndrome, Crohn's Disease, Vitiligo, and Alopecia Areata, Irritable Bowel Syndrome (IBS), Ulcerative Colitis, Parkinson's Disease, Alzheimer's Disease, Dermatitis, Hepatitis, Atherosclerosis, and Diverticulitis.

\section{Acknowledgement}

The authors are gratefully acknowledged to Trivedi science, Trivedi Global, Inc., and Trivedi master wellness and to Dabur Research Foundation (DRF), India for their support.

\section{References}

1. Ley R, Hamady M, Lozupone C, Turnbaugh P, Ramey R, et al. (2008) Evolution of mammals and their gut microbes. Science 320(5883): $1647-1651$.

2. Tomas J, Wrzosek L, Bouznad N, Bouet S, Mayeur C, et al. (2013) Primocolonization is associated with colonic epithelial maturation during conventionalization. FASEB J 27(2): 645-655.

3. Danese S, Mantovani A (2010) Inflammatory bowel disease and intestinal cancer: A paradigm of the yin-yang interplay between inflammation and cancer. Oncogene 29(23): 3313-3323.

4. Rubin DC, Shaker A, Levin MS (2012) Chronic intestinal inflammation: Inflammatory bowel disease and colitis-associated colon cancer. Front Immunol 3: 107 
5. Dai ZH, Tan B, Yang H, Wang O, Qian JM, Lv H (2015) 1,25-hydroxyvitamin $\mathrm{D}$ relieves colitis in rats via down-regulation of toll-like receptor 9 expression. Croat Med J 56(6): 515-524.

6. Thomas KJ, Nicholl JP, Coleman P (2001) Use and expenditure on complementary medicine in England: A population based survey. Complement Ther Med 9(1): 2-11.

7. Manya K, Champion B, Dunning T (2012) The use of complementary and alternative medicine among people living with diabetes in Sydney. BMC Complement Altern Med 12: 2-10.

8. Astin JA, Pelletier KR, Marie A, Haskell WL (2000) Complementary and alternative medicine use among elderly persons: One-year analysis of a blue shield medicare supplement. J Gerontol A Biol Sci Med Sci 55(1): M4-M9.

9. Barnes PM, Bloom B, Nahin RL (2008) Complementary and alternative medicine use among adults and children: United States, 2007. Natl Health Stat Report 12: 1-23.

10. Rubik B (2002) The biofield hypothesis: Its biophysical basis and role in medicine. J Altern Complement Med 8(6): 703-717.

11. Jain S, Hammerschlag R, Mills P, Cohen L, Krieger R, et al. (2015) Clinical studies of biofield therapies: Summary, methodological challenges, and recommendations. Glob Adv Health Med 4(Suppl): 58-66.

12. Fan K wai (2005) National center for complementary and alternative medicine website. J Med Libr Assoc 93: 410-412.

13. Frass M, Strassl RP, Friehs H, Mullner M, Kundi M, et al. (2012) Use and acceptance of complementary and alternative medicine among the general population and medical personnel: A systematic review. Ochsner J 12(1): 45-56.

14. Trivedi MK, Mohan TRR (2016) Biofield energy signals, energy transmission and neutrinos. American Journal of Modern Physics 5(6): 172-176.

15. Trivedi MK, Branton A, Trivedi D, Nayak G, Mondal SC, et al. (2015) Antimicrobial sensitivity, biochemical characteristics and biotyping of Staphylococcus saprophyticus: An impact of biofield energy treatment. J Women's Health Care 4(6): 271.

16. Trivedi MK, Patil S, Shettigar H, Mondal SC, Jana S (2015) In vitro evaluation of biofield treatment on Enterobacter cloacae: Impact on antimicrobial susceptibility and biotype. J Bacteriol Parasitol 6: 241.

17. Trivedi MK, Patil S, Shettigar H, Mondal SC, Jana S (2015) Evaluation of biofield modality on viral load of Hepatitis B and C Viruses. J Antivir Antiretrovir 7: 83-88.

18. Trivedi MK, Branton A, Trivedi D, Nayak G, Mondal SC, et al. (2015) Evaluation of antibiogram, genotype and phylogenetic analysis of biofield treated Nocardia otitidis. Biol Syst Open Access 4: 143.

19. Trivedi MK, Branton A, Trivedi D, Nayak G, Charan S, et al. (2015) Phenotyping and 16S rDNA analysis after biofield treatment on Citrobacter braakii: A urinary pathogen. J Clin Med Genom 3(3): 129.

20. Peoples JJ, Trivedi MK, Branton A, Trivedi D, Nayak G, et al. (2017) Skin rejuvenating effect of consciousness energy healing treatment based herbomineral formulation. American Journal of Plant Biology 2(3): 77 87.

21. Smith DM, Trivedi MK, Branton A, Trivedi D, Nayak G, et al. (2017) Skin protective activity of consciousness energy healing treatment based herbomineral formulation. Journal of Food and Nutrition Sciences 5(3): 86-95.

22. Weekes BA, Trivedi MK, Branton A, Trivedi D, Nayak G, et al. (2018) an alternative approach for the management of bone health: Role of biofield energy healing treated vitamin $\mathrm{D}_{3}$. American Journal of Internal Medicine 6(1): 1-9.

23. Piedad RB, Trivedi MK, Branton A, Trivedi D, Nayak G, et al. (2018) Exploring the effects of biofield energy treated vitamin $\mathrm{D}_{3}$ on bone health parameters in MG-63 cell line. International Journal of Food Science and Biotechnology 3(1): 15-22.

24. Patric E, Trivedi MK, Branton A, Trivedi D, Nayak G, et al. (2018) The influence of biofield energy treated vitamin $\mathrm{D}_{3}$ on bone health and its health consequences in MG-63 cell-line. Advances in Bioscience and Bioengineering 6(1): 1-9.

25. Trivedi MK, Branton A, Trivedi D, Nayak G, Gangwar M, et al. (2015) Analysis of genetic diversity using Simple Sequence Repeat (SSR) markers and growth regulator response in biofield treated cotton (Gossypium hirsutum L.). American Journal of Agriculture and Forestry 3(5): 216-221.

26. Trivedi MK, Branton A, Trivedi D, Nayak G, Gangwar M, et al. (2015) Evaluation of vegetative growth parameters in biofield treated bottle gourd (Lagenaria siceraria) and okra (Abelmoschus esculentus). International Journal of Nutrition and Food Sciences 4(6): 688-694.

27. Trivedi MK, Branton A, Trivedi D, Nayak G, Balmer AJ, et al. (2016) Evaluation of pro-inflammatory cytokines expression in mouse splenocytes after incubation with biofield treated herbomineral formulation: Effect of biofield energy healing treatment-The Trivedi Effect $^{\circledR}$. American Journal of Biomedical and Life Sciences 4(6): 87-97.

28. Trivedi MK, Branton A, Trivedi D, Nayak G, Ellis MP, et al. (2016) Evaluation of pro-inflammatory cytokines expression in mouse splenocytes after co-incubation with the biofield energy treated formulation: Impact of the Trivedi Effect ${ }^{\circledR}$. International Journal of Biomedical Science and Engineering 4(5): 40-49.

29. Trivedi MK, Patil S, Shettigar H, Bairwa K, Jana S (2015) Spectroscopic characterization of biofield treated metronidazole and tinidazole. Med Chem 5(7): 340-344.

30. Trivedi MK, Patil S, Shettigar H, Bairwa K, Jana S (2015) Effect of biofield treatment on spectral properties of paracetamol and piroxicam. Chem Sci J 6(3): 98.

31. Trivedi MK, Tallapragada RM, Branton A, Trivedi D, Nayak G, et al. (2015) Evaluation of atomic, physical, and thermal properties of bismuth oxide powder: An impact of biofield energy treatment. American Journal of Nano Research and Applications 3(6): 94-98.

32. Trivedi MK, Patil S, Nayak G, Jana S, Latiyal O (2015) Influence of biofield treatment on physical, structural and spectral properties of boron nitride. J Material Sci Eng 4(4): 181.

33. Murano M, Maemura K, Hirata I, Toshina K, Nishikawa T, et al. (2000) Therapeutic effect of intracolonically administered nuclear factor kappa B (p65) antisense oligonucleotide on mouse Dextran Sulphate Sodium (DSS)-induced colitis. Clin Exp Immunol 120(1): 51-58.

34. Wallace JL, Keenan CM (1990) An orally active inhibitor of leukotriene synthesis accelerates healing in a rat model of colitis. Am J Physiol 258(4 Pt 1): G527-G534.

35. Murthy SNS, Cooper HS, Shim H, Shah RS, Ibarahim SA, et al. (1993) Treatment of dextran sulfate sodium-induced murine colitis by intracolonic cyclosporin. Dig Dis Sci 38(9): 1722-1734.

36. Murphy TL, Cleveland MG, Kulesza P, Magram J, Murphy KM (1995) Regulation of interleukin 12 p40 expression through a NF- $\kappa B$ half-site. Mol Cell Biol 15(10): 5258-5267.

37. Dai ZH, Tan B, Yang H, Wang O, Qian JM, et al. (2015) 1,25-hydroxyvitamin $\mathrm{D}$ relieves colitis in rats via down-regulation of toll-like receptor 9 expression. Croat Med J 56(6): 515-524.

38. Lister RG (1987) The use of a plus-maze to measure anxiety in the mouse. Psychopharmacology (Berl) 92(2): 180-185.

39. O'Sullivan DJ (2000) Methods for analysis of the intestinal microflora. Curr Issues Intest Microbiol 1(2): 39-50.

40. Mei Q Xu J, Xiang L, Hu Y, Hu X, et al. (2005) Change of nitric oxide in experimental colitis and its inhibition by melatonin in vivo and in vitro. Postgrad Med J 81(960): 667-672. 
41. Patel SH, Rachchh MA, Jadav PD (2012) Evaluation of anti-inflammatory effect of anti-platelet agent-clopidogrel in experimentally induced inflammatory bowel disease. Indian J Pharmacol 44(6): 744-748.

For possible submissions Click below: 